mammography in the breast cancer screening in Asian women: a community-based follow-up study and meta analysis", Zhonghua Zhong Liu Za Zhi. 32(3), 212-216.

8. Mizuno S (2004), "Approach to Fine-needle Aspiration Cytology-negative Cases of breast cancer", Asian Journal of Surgery. 28(1), 13-17.

9. Muddegowda PH (2011), "The value of systematic pattern analysis in FNAC of breast lesions: 225 cases with cytohistological correlation", J Cytol. 28(1), 13-19.

\title{
TỶ SUẤT TÂN SINH NGUYÊN BÀO NUÔI VÀ CÁC YẾU TỐ LIÊN QUAN TRÊN BỆNH NHÂN THAI TRỨNG LỚN TUỔI TẠI BÊ̂NH VIỆN TỪ DŨ
}

\section{TÓM TẮT}

Đặt vấn đề: Thai trứng (TT) ở bệnh nhân lớn tuổi có nguy cơ cao diễn tiến đến tân sinh nguyên bào nuôi (TSNBN). Ngoài hút nạo thai trứng là điều trị chính, các biện pháp dự phòng như hóa dự phòng, cắt tử cung dự phòng hay kết hợp hóa dự phòng và cắt tử cung được thực hiện với mục đích giảm nguy cơ bi TSNBN. Biết được tỷ suất TSNBN ở bệnh nhân TT lớn tuổi và hiệu quả các biện pháp dự phòng sau hút nạo giúp cho việc tư vấn, lựa chọn phương pháp điều trị bệnh được tốt hơn. Mục tiêu: Xác định tỷ suất tân sinh nguyên bào nuôi (TSNBN) và các yếu tố liên quan ở những trường hợp thai trứng (TT) lớn tuổi. Phương pháp: Nghiên cứu đoàn hệ hồi cứu trên 372 trường hợp thai trứng $\geq 40$ tuổi được chẩn đoán qua giải phẫu bềnh sau hút nạo tai bênh viện Từ Dũ từ 01/2016 đến 03/2019. Kết quá: Sau 2 năm theo dõi, 123 bệnh nhân tiến tiển đến TSNBN, tỷ suất TSNBN là 33.06\% (KTC 95\%:28.30-38.10). Thời gian xảy ra TSNBN trung bình là $4.15 \pm 2.93$ tuần, cao nhất ở tuần thứ 2 và tuần thứ 3 sau hút nạo. Sau phân tích đa biến tỷ suất TSNBN cao hơn đáng kể ở nhóm $\geq 46$ tuổi so với nhóm 40-45 tuổi ( $H R=1.63$ KTC 95\%:1.09-2.44), nhóm có triệu chứng ra huyết âm đạo so với nhóm không ra huyết (HR=1.85 KTC 95\%:1.16-2.96). Cắt tử cung dự phòng và hóa dự phòng kêt hợp cắt tứ cung làm giảm nguy cơ TSNBN so với nhóm không can thiệp với HR lần lượt là 0.16 (KTC 95\%:0.09-0.30) và 0.09 (KTC 95\%:0.04-0.21). Hóa dự phòng đơn thuần không làm giảm nguy cơ TSNBN so với nhóm không can thiệp, với $H R=0.74$ (KTC 95\%:0.21-2.62). Kết Iuận: Tỳ suất TSNBN hậu thai trứng ở các bênh nhân lớn tuổi là $33.06 \%$. Cắt tử cung dư phòng và hóa dư phòng kết hợp cắt tử cung là phương pháp điêu trị hiệu quả, giúp giảm nguy cớ TSNBN.

Tư khóa: Thai trứng, tân sinh nguyên bào nuôi, cắt tử cung dự phòng, hóa dự phòng.

\footnotetext{
${ }^{1}$ Đại học Y Dược TP Hồ Chí Minh

²Bệnh viện Từ Dũ

Chiu trách nhiệm chính: Võ Minh Tuấn

Email: vominhtuan@ump.edu.vn

Ngày nhận bài: 2.4.2021

Ngày phản biện khoa học: 17.5.2021

Ngày duyệt bài: 25.5.2021
}

\author{
Phan Thị Thúy Vân ${ }^{1}$, Võ Minh Tuấn ${ }^{1}$, \\ Võ Thanh Nhân ${ }^{2}$, Nguyễn Thị Hiền ${ }^{2}$
}

\section{SUMMARY}

\section{GESTATIONAL TROPHOBLASTIC NEOPLASIA RATE AND ASSOCISTED FACTORS OF HYDATIDIFORM MOLE IN ELDERLY PATIENT AT TU DU HOSPITAL}

Background: Hydatidiform mole (HM) in elderly patient has a high-risk developing post molar gestational trophoblastic neoplasia (GTN). Uterine evacuation is main method to treat HM. There are some prophylactic methods, they are prophylactic hysterectomy, chemotherapy or combining hysterectomy and chemotherapy. The purpose of utilizing these methods is to decrease risk of progressing GTN. The acknowledge of effectively prophylactic methods and rate of GTN in women older than 40 years of age which is useful for consulting and selecting suitable method of treatment. Objective: The study aimed to determine the GTN rate and asscociated factors associated of $\mathrm{HM}$ in elderly patients. Methods: This is a retrospective cohort study with 372 patients older than 40 years-old who were diagnosed $\mathrm{HM}$ based on histology by uterine evacuation at TuDu hospital from 01/2016 to 03/2019. Results: Followed-up by 2 years, 123 patients developed GTN, the incidence of GTN was $33.06 \%$ (95\%CI:28.3-38.1). The median time progressed GTN which was $4.15 \pm 2.93$ weeks. The highest rate of GTN was recognized at the second and third week after evacuation. Applying multivariate model, the rate of GTN was significantly higher in group older than 46 years of age than group 40-45 years-old $(H R=1.63$, $95 \% \mathrm{CI}: 1.09-2.44)$ and in vaginal bleeding group than none bleeding group (HR=1.85, 95\%CI:1.16-2.96). Prophylactic hysterectomy or combined with chemotherapy reducing risk of progressing to GTN more than group which was not intervened $(\mathrm{HR}=0.16$, 95\%CI:0.09-0.30) and ( $\mathrm{HR}=0.09,95 \% \mathrm{CI}=0.04-0.21)$ respectively. Prophylactic chemotherapy was not impact on diminishing risk of GTN $(H R=0.74$, 95\%CI:0.21-2.62). Conclusions: The rate of postmolar GTN in elderly patient was $33.06 \%$. Prophylactic hysterectomy and chemotherapy was effective treatment and helpful to decrease risk of GTN.

Key words: hydatidiform mole, gestational trophoblastic neoplasia, prophylactic hysterectomy, prophylactic chemotherapy 


\section{I. ĐĂT VẤN ĐỀ}

Tuổi me $\geq 40$ tuổi làm tăng nguy cơ mắc thai trứng gấp 5-10 lần cũng như tăng nguy cơ diễn tiến đến TSNBN sau hút nạo, tần suất TSNBN ở phu nữ $\geq 40$ tuổi khoảng $22-37 \%$, ở phụ nữ $>50$ tuổi tần suất này tăng rất cao, khoảng 3156\%[6]. Các biện pháp dự phòng như hóa dự phòng, cắt tử cung dự phòng, hay kết hợp hóa dự phòng và cắt tứ cung dự phòng thường được áp dụng để giảm nguy cơ diên tiến đến TSNBN. Tuy nhiên hiệu quả của các biện pháp dự phòng còn gây tranh cải[4],[7],[8]. Biết được tỷ suất TSNBN và các yếu tố liên quan cũng như hiệu quả của các biện pháp dự phòng giúp cho việc tư vấn, lựa chọn phương pháp điều trị, quản lý và theo dõi bênh được tốt hơn.

Việt Nam nằm trong vùng dịch tễ mắc bệnh thai trứng cao. Theo số liệu thống kê hàng năm Khoa Ung bướu phụ khoa bệnh viện Từ Dũ tiếp nhận điều trị và theo dõi 800-1000 ca thai trứng, trong đó có khoảng 160-180 trường hợp $\geq 40$ tuổi. Tai Viêt Nam gần đây chưa có nhiều nghiên cứu về thai trứng ở các bệnh nhân lớn tuổi vì vậy chúng tôi thực hiện nghiên cứu này.

Mục tiêu nghiên cứu: Xác định tỷ suất TSNBN và các yếu tố liên quan trên bệnh nhân thai trứng lớn tuổi tại bệnh viện Từ Dũ.

\section{II. ĐỐI TƯợNG VÀ PHƯƠNG PHÁP NGHIÊN CứU}

Đối tượng nghiên cứu: Những bệnh nhân được chẩn đoán xác định là thai trứng dựa trên kết quả giải phẫu bệnh có độ tuổi $\geq 40$ được theo dõi và điêuu trị tại khoa Ung Bướu Phụ Khoa bệnh viện Từ Dũ từ 01/2016-03/2019

Tiêu chuẩn nhận vào: giải phẫu bệnh sau hút nao là $T$, không có bằng chứng của xâm lấn tại chỗ hoặc di căn, được theo dõi theo phác đồ bệnh viện Từ Dũ trong 2 năm hoặc đến khi hết bểnh (tổi thiểu 6 tháng sau khi $\beta$-hCG về âm tính đối với TT nguy cơ thấp và 12 tháng đối với $T T$ nguy cơ cao).

Tiêu chuẩn loại trừ: có thai trong quá trình theo dõi, cắt tử cung vì các nguyên nhân khác không phải do bệnh nguyên bào nuôi thai kỳ trong quá trình theo dõi, bỏ theo dõi trong quá trình điều trị, hồ sơ bệnh án không đủ thông tin.

\section{Phương pháp nghiên cứu}

Thiết kế nghiên cứu: Đoàn hệ hồi cứu

Cỡ mẫu. Công thức ước lượng tỷ lệ trong quần thể với độ chính xác tuyệt đối

$$
n=\frac{Z_{\left(1-\frac{\alpha}{2}\right)}^{2} P \cdot(1-P)}{d^{2}}
$$

Trong đó: n là cõ̃ mẫu cần thiết tối thiểu đủ đảm bảo năng lực mấu cho mục tiêu.

Chọn $a=0,05 \rightarrow Z=1,96$ (với khoảng tin câyy $95 \%)$. d là độ chính xác tuyệt đối $5 \%$.

Theo nghiên cứu của Tow, Savage, Tsukmoto và cộng sự đã báo cáo rằng tỷ lệ diễn tiến đến TSNBN ở những trường họp thai trứng $\geq 40$ tuổi vào khoảng 23-37\%[6]. Do tỷ lệ dao động lớn, chúng tôi chọn $p=0.37$ để có mẫu với năng lực mẫu lớn nhất $n=359$.

Biến số nghiên cứu. TSNBN được chẩn đoán theo tiêu chẩn FIGO 2000 bao gồm: $\beta$-hCG tăng $>10 \%$ qua 3 lần xét nghiệm liên tiếp trong 2 tuần (ngày $1,7,14$ ), $\beta$-hCG bình nguyên qua 4 lần xét nghiệm liên tiếp trong 3 tuần (ngày $1,7,14,21), \beta$-hCG tồn tại kéo dài 6 tháng, chẩn đoán giải phẫu bệnh là choriocarcinoma, các trường hợp có giải phẫu bệnh sau cắt tử cung là thai trứng xâm lấn (TTXL) cũng được xếp vào nhóm TSNBN.

Thời gian TSNBN (tuần) được tính từ lúc hút nạo tới lúc chẩn đoán TSNBN.

Phương pháp thực hiện:

Lây mầu toàn bộ. Dùng phần mềm quản lý hồ sơ bệnh án tại khoa, lọc tìm những hồ sơ được chẩn đoán là thai trứng có độ tuổi $\geq 40$ tuổi nhập viện từ $01 / 2016$ đên $03 / 2019$ ghi lại sô nhập viện, năm nhập viện, tên, năm sinh.

Từ những thông tin trên, sẽ lục tìm bệnh án tại Phòng lưu trữ hồ sơ bệnh viện Từ Dũ. Chọn những hồ sơ thỏa tiêu chuẩn chọn mẫu, loại bỏ những hồ sơ có tiêu chuẩn loai trừ.

Dữ liệu được thu thập từ hồ sơ bệnh án và hồ sơ ngoại trú theo bảng thu thập số liệu bao gồm: thông tin dịch tễ cơ bản, đặc điểm bệnh thai trứng, biện pháp điều trị sau hút nạo, thời gian xảy ra TSNBN.

Số liệu được phân tích bằng phần mềm STATA 14. Sử dụng phương pháp bảng sống để ước tính tỷ suất TSNBN tích lũy. So sánh thời gian sống còn giữa các nhóm bằng phép kiểm Logrank. Sử dụng mô hình hồi quy Cox đơn biến và đa biến để xác định mối liên quan giữa các yếu tố với TSNBN. Các biến trong mô hình hồi quy Cox đa điến bao gồm các biến có giá trị $\mathrm{p}<0.25$ trong phân tích đơn biến và một số biến đã được biết là có liên quan đến TSNBN. Ý nghĩa thống kê được xác định khi $p<0.05$

Giấy phép y đức. Nghiên cứu thực hiện khi được Hội đồng nghiên cứu khoa học, Hội đồng Đạo Đức trong nghiên cứu y sinh học Đại học Y Dược TP Hồ Chí Minh thông qua theo biên bản chẩp nhận cho phép nghiên cứu khoa học số 653/HĐĐĐ-ĐHYD ngày 06/10/2020 và Hội đồng 
nghiên cứu khoa học bệnh viện Từ Dũ thông qua theo Quyết định số 2660/QĐ-BVTD ngày 17/11/2020.

\section{KẾT QUẢ NGHIÊN CỨU}

Trong số 372 bệnh nhân được đưa vào nghiên cứu từ 01/2016 đến 03/2019, 123 bệnh nhân diễn tiến đến TSNBN. Các đặc điểm về dịch tễ và bệnh thai trứng được trình bày trong Bảng 1. Các bệnh nhân có độ tuổi từ 40-57 tuổi, trung bình là 46 tuổi. Đa số bệnh nhân đã sinh $\geq 2$ lần (84.95\%). Triệu chứng thường gặp nhất là trễ kinh $(77.69 \%)$ và ra huyết âm đạo (60.75\%).
Phần lớn bệnh nhân có kích thước tử cung $\leq 12$ tuần và nồng độ $\beta$-hCG trước hút nạo $\geq 100000$ $\mathrm{mIU} / \mathrm{ml}$. Nang hoàng tuyến $\geq 6 \mathrm{~cm}$, biến chứng nội khoa nặng như cường giáp, tiền sản giật, thuyên tắc tế bào nuôi rất hiếm gặp. Phẫu thuật cắt tử cung dự phòng là phương pháp quản lý sau hút nạo thường được áp dụng. Trong phân tích ban đầu về tỷ lệ giữa các nhóm, TSNBN khác biêt có ý nghĩa thống kê ở các đặc điểm: trễ kinh, ra huyết âm đạo, kích thước tử cung, thiếu máu, nồng độ $\beta$-hCG trước hút nạo và phân loai nguy cơ thai trứng WHO-1983.

Bảng 1: Đặc điểm dịch tễ và lâm sàng các bệnh nhân thai trứng

\begin{tabular}{|c|c|c|c|c|c|}
\hline \multicolumn{2}{|c|}{ Đặc điểm } & $\begin{array}{l}\text { Tống } \\
\text { N(\%) }\end{array}$ & $\begin{array}{l}\text { Lui bênh } \\
N=249(\%)\end{array}$ & $\begin{array}{c}\text { TSNBN } \\
N=123(\%)\end{array}$ & $\mathbf{p}^{*}$ \\
\hline Tuổi & $\begin{array}{c}40-45 \\
\geq 46\end{array}$ & $\begin{array}{l}177(47.58) \\
195(52.42)\end{array}$ & $\begin{array}{l}125(70.62) \\
124(63.59)\end{array}$ & $\begin{array}{l}52(29.38) \\
71(36.41)\end{array}$ & 0.101 \\
\hline $\begin{array}{c}\text { Số lần sinh } \\
\text { tuần }\end{array}$ & $\begin{array}{c}\text { Chưa sinh } \\
1 \text { lần } \\
\geq 2 \text { lần }\end{array}$ & $\begin{array}{c}11(2.96) \\
45(12.10) \\
316(84.95)\end{array}$ & $\begin{array}{c}10(90.91) \\
30(66.67) \\
209(66.14)\end{array}$ & $\begin{array}{c}1(9.09) \\
15(33.33) \\
107(33.86)\end{array}$ & 0.271 \\
\hline $\begin{array}{l}\text { Tiên căn bệnh lý } \\
\text { nguyên bào nuối }\end{array}$ & $\begin{array}{l}\text { Không } \\
\text { Có }\end{array}$ & $\begin{array}{c}367(98.66) \\
5(1.34) \\
\end{array}$ & $\begin{array}{c}245(66.76) \\
4(80.00)\end{array}$ & $\begin{array}{c}122(33.24) \\
1(20.00)\end{array}$ & 0.494 \\
\hline Trễ kinh & $\begin{array}{l}\text { Không } \\
\text { Có }\end{array}$ & $\begin{array}{c}83(22.31) \\
289(77.69)\end{array}$ & $\begin{array}{c}48(57.83) \\
201(69.55)\end{array}$ & $\begin{array}{l}35(42.17) \\
88(30.45)\end{array}$ & 0.018 \\
\hline Ra huyết & $\begin{array}{l}\text { Không } \\
\text { Có }\end{array}$ & $\begin{array}{l}146(39.25) \\
226(60.75)\end{array}$ & $\begin{array}{l}115(78.77) \\
134(59.29)\end{array}$ & $\begin{array}{l}31(21.23) \\
92(40.71)\end{array}$ & 0.000 \\
\hline Đau bụng & $\begin{array}{l}\text { Không } \\
\text { Có }\end{array}$ & $\begin{array}{l}283(76.08) \\
89(23.92)\end{array}$ & $\begin{array}{l}194(68.55) \\
55(61.80)\end{array}$ & $\begin{array}{l}89(31.45) \\
34(38.20)\end{array}$ & 0.200 \\
\hline Buồn nôn, nôn & $\begin{array}{l}\text { Không } \\
\text { Có }\end{array}$ & $\begin{array}{l}284(76.34) \\
88(23,66)\end{array}$ & $\begin{array}{c}195(68.66) \\
54(61.36)\end{array}$ & $\begin{array}{l}89(31.34) \\
34(38.64)\end{array}$ & 0.264 \\
\hline $\begin{array}{l}\text { Kích thước tử } \\
\text { cung }\end{array}$ & $\begin{array}{l}\leq 12 \text { tuân } \\
>12 \text { tuần }\end{array}$ & $\begin{array}{l}273(73.39) \\
99(26.61)\end{array}$ & $\begin{array}{l}200(73.26) \\
49(49.49)\end{array}$ & $\begin{array}{l}73(26.74) \\
50(51.51)\end{array}$ & 0.000 \\
\hline $\begin{array}{l}\text { Nang hoàng } \\
\text { tuyến }\end{array}$ & $\begin{array}{l}\text { Không } \\
<6 \mathrm{~cm} \\
\geq 6 \mathrm{~cm}\end{array}$ & $\begin{array}{c}349(93.83) \\
18(4.84) \\
5(1.34)\end{array}$ & $\begin{array}{c}236(67.62) \\
10(55.56) \\
3(60.00)\end{array}$ & $\begin{array}{c}113(32.38) \\
8(44.44) \\
2(40.00)\end{array}$ & 0.520 \\
\hline Tiền sản giật & $\begin{array}{l}\text { Không } \\
\text { Có }\end{array}$ & $\begin{array}{c}361(97.04) \\
11(2,96)\end{array}$ & $\begin{array}{c}247(67.31) \\
6(54.55)\end{array}$ & $\begin{array}{c}118(32.69) \\
5(45.45)\end{array}$ & 0.228 \\
\hline Cường giáp & $\begin{array}{l}\text { Không } \\
\text { Có }\end{array}$ & $\begin{array}{c}367(98.66) \\
5(1.34)\end{array}$ & $\begin{array}{c}247(67.30) \\
2(40.00)\end{array}$ & $\begin{array}{c}120(32.70) \\
3(60.00)\end{array}$ & 0.149 \\
\hline $\begin{array}{c}\text { Thuyên tắc tế bào } \\
\text { nuôi }\end{array}$ & $\begin{array}{l}\text { Không } \\
\text { Có }\end{array}$ & $\begin{array}{c}372(100) \\
0\end{array}$ & $\begin{array}{c}249(66.94) \\
0\end{array}$ & $\begin{array}{c}123(33.06) \\
0\end{array}$ & 0.000 \\
\hline Thiếu máu & $\begin{array}{l}\text { Không } \\
\text { Có }\end{array}$ & $\begin{array}{l}215(57.80) \\
157(42.20)\end{array}$ & $\begin{array}{l}153(71.16) \\
96(61.15)\end{array}$ & $\begin{array}{l}62(28.84) \\
61(38.85)\end{array}$ & 0.019 \\
\hline $\begin{array}{c}\text { B-hCG trước hút } \\
\text { nạo }(\mathrm{mIU} / \mathrm{ml})\end{array}$ & $\begin{array}{l}<100000 \\
\geq 100000\end{array}$ & $\begin{array}{c}81(21.77) \\
291(78.23)\end{array}$ & $\begin{array}{l}\text { 64(79.01) } \\
185(63.57)\end{array}$ & $\begin{array}{l}17(20.99) \\
106(36.43)\end{array}$ & 0.009 \\
\hline GPB sau hút nạo & $\begin{array}{l}\text { TTBP } \\
\text { TTTP }\end{array}$ & $\begin{array}{l}127(34.14) \\
245(65.86)\end{array}$ & $\begin{array}{c}89(70.08) \\
160(65.31)\end{array}$ & $\begin{array}{l}38(29.92) \\
85(34.69)\end{array}$ & 0.259 \\
\hline $\begin{array}{l}\text { Phân loại nguy cơ } \\
\text { TT WHO-1983 }\end{array}$ & $\begin{array}{l}\text { Nguy cơ thấp } \\
\text { Nguy cơ cao }\end{array}$ & $\begin{array}{c}69(18.55) \\
303(81.45)\end{array}$ & $\begin{array}{c}55(79.71) \\
194(64.03)\end{array}$ & $\begin{array}{c}14(20.29) \\
109(35.97)\end{array}$ & 0.012 \\
\hline $\begin{array}{c}\text { Quản lý sau hút } \\
\text { nạo }\end{array}$ & $\begin{array}{l}\text { Không can thiệp } \\
\text { Hóa dự phòng } \\
\text { Cắt tử cung } \\
\text { Hóa dứ phòng + cắt } \\
\text { tử cung }\end{array}$ & $\begin{array}{c}83(22.31) \\
7(1.88) \\
251(67.47) \\
31(8.33)\end{array}$ & $\begin{array}{c}55(66.27) \\
4(57.14) \\
171(68.13) \\
19(61.29)\end{array}$ & $\begin{array}{c}28(33.73) \\
3(42.86) \\
80(31.87) \\
12(38.71)\end{array}$ & 0.831 \\
\hline
\end{tabular}


p*: phép kiểm Log rank testCác bệnh nhân được theo dõi trong vòng 2 năm, tỷ suất TSNBN tích lũy sau $2,3,4$ và 16 tuần là $11.83 \%, 17.47 \%$, $22.31 \%$ và $33.06 \%$ (Bảng 2 ). Thời gian chẩn đoán TSNBN trung bình là 4.15 \pm 2.93 tuần, sớm nhất là 1 tuần, trế nhất là 16 tuần. Tỳ suất TSNBN xảy ra nhiều nhất trong vòng 4 tuần đầu sau hút nạo, đặc biệt là tuần thứ 2 và tuần thứ 3 .

Bảng 2: Tỷ suât tân sinh nguyên bào nuôi theo thời gian

\begin{tabular}{|c|c|c|c|}
\hline $\begin{array}{c}\text { Thời } \\
\text { gian } \\
\text { (tuân) }\end{array}$ & $\begin{array}{c}\text { Không } \\
\text { TSNBN }\end{array}$ & $\begin{array}{c}\text { TS } \\
\text { NBN }\end{array}$ & $\begin{array}{c}\text { Uớc tính tỷ suất } \\
\text { tích lũy TSNBN } \\
\text { (95\% KTC) }\end{array}$ \\
\hline 1 & 372 & 16 & $4.3(2.7-6.9)$ \\
2 & 356 & 28 & $11.8(8.9-15.6)$ \\
3 & 328 & 21 & $17.5(14.0-21.7)$ \\
4 & 307 & 18 & $22.3(18.4-26.9)$ \\
5 & 289 & 9 & $24.7(20.7-29.4)$ \\
6 & 280 & 10 & $27.4(23.2-32.3)$ \\
7 & 270 & 4 & $28.5(24.2-33.4)$ \\
8 & 266 & 7 & $30.4(26.0-35.2)$ \\
9 & 259 & 3 & $31.2(26.7-36.2)$ \\
10 & 256 & 1 & $31.5(27.0-36.4)$ \\
11 & 255 & 2 & $32.0(27.5-37.0)$ \\
12 & 253 & 2 & $32.5(28.0-37.6)$ \\
\hline
\end{tabular}

\begin{tabular}{|c|l|l|l|}
\hline 14 & 251 & 1 & $32.8(28.3-37.8)$ \\
16 & 250 & 1 & $33.1(28.5-38.1)$ \\
17 & 249 & 0 & $33.1(28.5-38.1)$ \\
104 & 249 & 0 & $33.1(28.5-38.1)$ \\
\hline
\end{tabular}

Trong mô hình hồi quy Cox đa biến (Bảng 3), chúng tôi ghi nhận 3 yếu tố liên quan có ý nghĩa thống kê với tỷ suất TSNBN. Bệnh nhân $\geq 46$ tuổi làm tăng nguy cơ bị TSNBN gấp 1.63 lần so với các bệnh nhân 40-45 tuổi (HR=1.63, KTC 95\%:1.09-2.44). Tương tự bệnh nhân có triệu chứng ra huyết âm đạo làm tăng nguy cơ bị TSNBN gấp 1.85 lần so với nhóm không ra huyết âm đạo ( $\mathrm{HR}=1.85$, KTC 95\%:1.16-2.96). Về phương pháp quan lý sau hút nạo, các bệnh nhân được cắt tử cung dự phòng làm giảm nguy cơ bị TSNBN 84\% so với nhóm không can thiệp ( $\mathrm{HR}=0.16$, KTC 95\%:0.09-0.30), hóa dự phòng kết hợp cắt tử cung làm giảm nguy cơ bị TSNBN $91 \%$ so với nhóm không can thiệp ( $\mathrm{HR}=0.09$, KTC 95\%:0.04-0.21), hóa dự phòng đơn thuần không làm giảm nguy cơ TSNBN so với nhóm không can thiệp (HR=0.74, KTC 95\%:0.21-2.62).

\section{Bảng 3: Môi liên quan giữa các yếu tố và TSNBN}

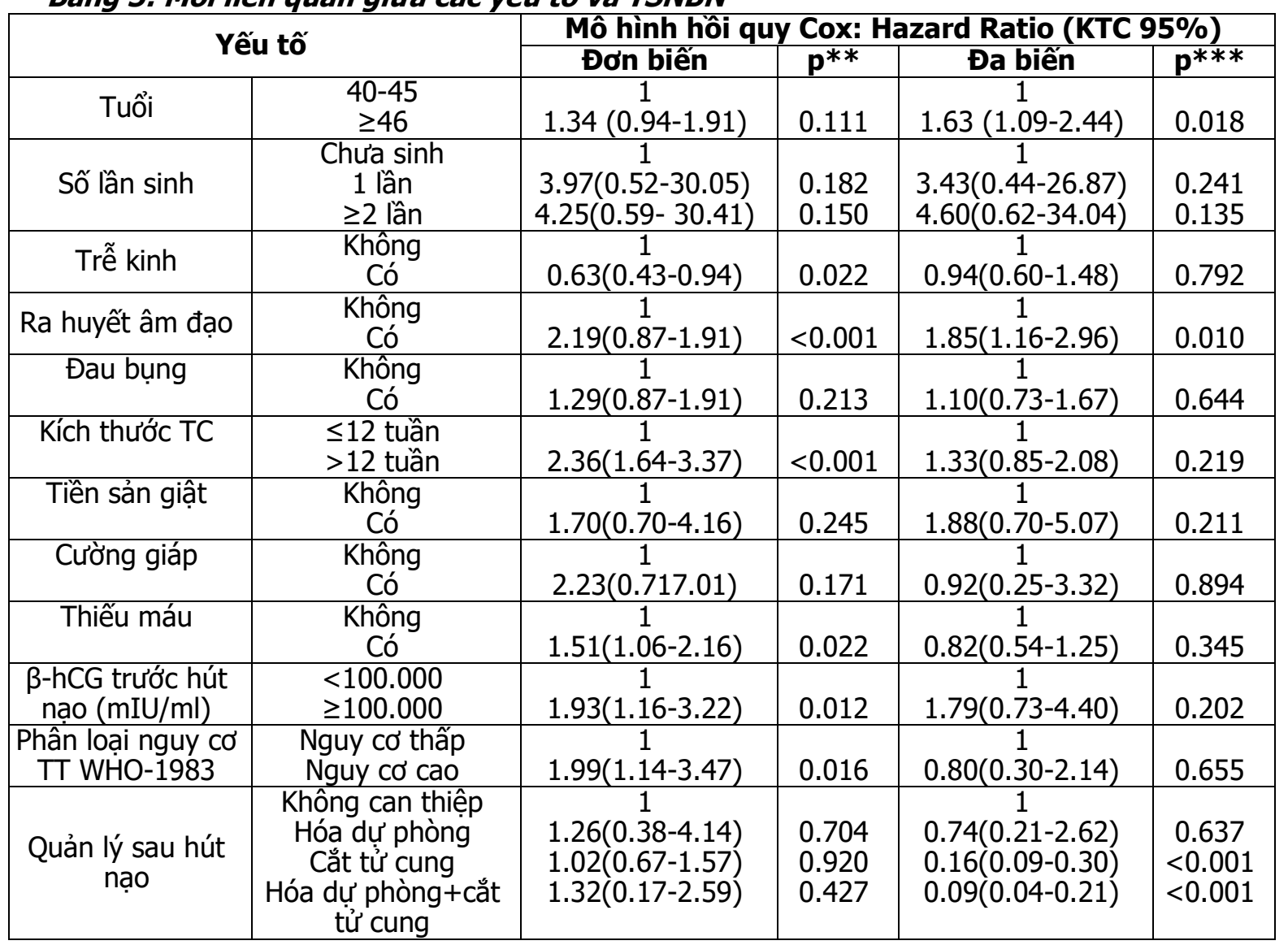




\begin{tabular}{|c|c|c|c|c|c|}
\hline TTXL & $\begin{array}{l}\text { Không } \\
\text { Có }\end{array}$ & - & - & $\begin{array}{c}1 \\
40(22.93-69.66)\end{array}$ & $<0.001$ \\
\hline
\end{tabular}

\section{BÀN LUÂN}

Nghiên cứu thực hiện trên 372 bệnh nhân thai trứng $\geq 40$ tuổi, tỷ suất TSNBN là $33.06 \%$, tương đương với các nghiên cứu ở các quốc gia khác là $32.16 \%$ trong nghiên cứu của Peng Zhao[8] và $34.21 \%$ trong nghiên cứu của Giorgione[4]. Trong khi đó thai trứng ở độ tuổi trẻ hơn có tỷ suất TSNBN thấp hơn, vào khoảng $15-20 \%[2]$. Vậy bệnh nhân thai trứng lớn tuổi có nguy cơ cao bị TSNBN hơn so với các bệnh nhân trẻ tuổi.

TTLX được xếp vào nhóm TSNBN làm thay đổi tỷ lệ TSNBN giữa các nhóm quản lý sau hút nạo ảnh hưởng đến việc đánh giá hiệu quả các biện pháp quản lý sau hút nạo. Vì vậy ngoài đưa các yếu tố có $p<0,25$ trong phân tích đơn biến vào phân tích đa biến, chúng tôi đưa thêm yếu tố biện pháp quản lý sau hút nạo và $T T X L$ vào phân tích đa biến để khống chế tác động gây nhiễu. Sau khi phân tích đa biến chúng tôi ghi nhận được 3 yếu tố liên quan đến TSNBN là tuổi, ra huyết âm đạo, biện pháp quản lý sau hút nạo.

Triệu chứng ra huyết âm đạo làm tăng nguy cơ bị TSNBN gấp 1.85 lần so với nhóm không ra huyết âm đạo. Tuy nhiên trong các nghiên cứu khác không tìm thây mối liên quan này[2],[8]. Sự khác biệt này có thể do dân số nghiên cứu khác nhau, độ tuổi nghiên cứu khác nhau, sự khác nhau về cõ̃ mẫu cùng với đây là triệu chứng cơ năng phụ thuộc vào sự nhận biết và khai báo của bệnh nhân nên có thể ảnh hưởng đến tỷ lệ xuất hiện của triệu chứng trong các nghiên cứu, dẫn đến sự khác biệt trong kết quả về mối liên quan đến TSNBN.

Tuổi được biết như là một yếu tố nguy cơ của TSNBN, sau phân tích đa biến cho thấy bệnh nhân $\geq 46$ tuổi tăng nguy cơ bị TSNBN gấp 1.63 lần (KTC 95\%:1.09-2.44) so với nhóm 40-45 tuổi. Trong nghiên cứu của Peng Zhao trên các bệnh nhân lớn hơn 40 tuổi lại cho thấy yếu tố tuổi không có mối liên quan đến TSNBN, khác biệt này có thể do nghiên cứu Peng Zhao chỉ bao gồm TTTP, mà TTTP được biết là có nguy cơ bị TSNBN cao hơn TTBP, nên gây ảnh hưởng đến mối liên quan giữa tuối và TSNBN.

Hóa dự phòng đơn thuần ở các bệnh nhân lớn tuổi không làm giảm tỷ suất TSNBN so với nhóm không can thiệp. Kết quả này cũng được ghi nhận tương tự ở nghiên cứu nước ngoài của Peng Zhao[8] và một số nghiên cứu khác[3],[5]. Nghiên cứu trong nước của tác giả Trần Nhật
Huy, Võ Minh Tuấn trên các bệnh nhân thai trứng nguy cơ cao cũng cho thấy khồng có sự khác biệt về nguy cơ bị TSNBN giữa 2 nhóm có hóa dự phòng hay không hóa dự phòng[1]. Vậy hóa dự phòng ở các bệnh nhân mọi độ tuổi hay các bệnh nhân lớn tuổi đều không làm giảm nguy cơ TSNBN, cùng với tác dụng phụ của hóa trị và tăng nguy cơ kháng thuốc khi bệnh diễn tiến đến TSNBN, chúng ta không cần áp dụng hóa dự phòng cho dù bệnh nhân lớn tuổi, điều này giúp giảm chi phí và tác dụng ngoại ý không đáng có.

Cắt tử cung dự phòng ở các bệnh nhân thai trứng $\geq 40$ tuổi là một biện pháp dự phòng hiệu quả, giúp giảm tỷ suất TŚNBN $84 \%$ so với nhóm không can thiệp. Hiệu quả của cắt tử cung dự phòng cũng đã được ghi nhận trong các nghiên cứu trước đây[8]. Tuy nhiển nghiên cứu của Giorgione năm 2017 trên 76 bệnh nhân thai trứng $\geq 40$ tuổi lại đưa ra kết luận cắt tử cung nguyên phát không giúp làm giảm tỷ lệ TSNBN[4], sự khác biệt này do cắt tử cung nguyên phát từ đầu có thể bao gồm những trường hợp thai trứng đã bị TSNBN nên làm tăng tỷ lệ TSNBN trong nhóm cắt tử cung từ đó làm giảm hiệu quả của cắt tử cung. Vậy ở các bệnh nhân thai trứng $\geq 40$ tuổi, cắt tử cung dự phòng là một biện pháp quản lý hiệu quả, nên được áp dụng, giúp giảm nguy cơ bị TSNBN.

Hóa dự phòng trước khi cắt tử cung làm giảm nguy cơ bị TSNBN 91\% so với nhóm không can thiệp. Tuy nhiên nhóm này chỉ có 31 trường hợp chiếm $8.33 \%$ các bênh nhân trong nghiên cứu, năng lực mẫu có thể chưa đủ để kết luận vai trò của kết hợp điều trị này so với cắt tử cung không hóa dự phòng. Chúng tôi chưa tìm thấy sự so sánh giữa nhóm cắt tử cung có và không có hóa dự phòng ở các nghiên cứu khác về thai trứng, nhưng số liệu nghiên cứu chỉ ra đây có thể là phối hợp điều trị dự phòng tốt cho các bệnh nhân thai trứng lớn tuổi.

Hạn chế của nghiên cứu: đây là nghiên cứu đoàn hệ hồi cứu lệ thuộc hoàn toàn vào hồ sơ bệnh án nên khó tránh khỏi sai lệch, thiếu sót thông tin. Một số biến được đánh giá mang tính chủ quan phụ thuộc vào bệnh nhân như ngày kinh chót, thời gian trễ kinh, các triệu chứng cơ năng, và một số biến phụ thuộc chủ quan vào đánh giá của bác sĩ lâm sàng như kích thước tử cung, tử cung lớn hơn tuổi thai có thể ảnh hưởng đến kết quả của nghiên cứu. 
Tính ứng dụng của nghiên cứu: Biết được tỷ suất cao trở thành TSNBN ở các bệnh nhẩn thai trứng lớn tuổi, Đánh giá được hiệu quả của các biện pháp dự phòng: cắt tử cung giúp làm giảm nguy cơ bị TSNBN, hóa dự phòng kết hợp với cắt tử cung cũng là lựa chọn tốt cho các bệnh nhân thai trứng lớn tuổi. Hóa dự phòng đơn thuần không làm giảm nguy cơ bị TSNBN ở các bệnh nhân thai trứng lớn tuổi. Qua đó giúp bác sĩ lâm sàng lựa chọn biện pháp quản lý sau hút nạo phù hợp, tư vấn tốt hơn giúp bệnh nhân hiểu và tuân thủ điều trị.

\section{KẾT LUẬN}

Tỷ suất TSNBN ở các bệnh nhân thai trứng lớn tuổi là $33.06 \%$. Các yểu tố liên quan đến TSNBN bao gồm tuổi $\geq 46$ và có triệu chứng ra huyết âm đạo. Phẫu thuật cắt tử cung dự phòng có hiệu quả ở các bệnh nhân thai trứng lớn tuổi, đủ con, giúp làm giảm nguy cơ TSNBN. Hóa dự phòng đơn thuần không nên thực hiện do không làm giảm nguy cơ bị TSNBN.

\section{TÀl LIẸU THAM KHẢO}

1. Trân Huy Nhât, Võ Tuấn Minh, Lê Tư Phương

Chi (2014). "Kết quả hóa dự phòng ở bệnh nhân thai trứng nguy cơ cao tại bểnh viện Từ Dũ". Tập san Y học TP HCM, tập 18 (1), pp. 58-63.
2. Bakhtiyari Mahmood, Mirzamoradi Masoumeh, Kimyaiee Parichehr, et al. (2015). "Postmolar gestational trophoblastic neoplasia: beyond the traditional risk factors". Fertility and sterility, 104 (3), pp. 649-654.

3. Fu J., Fang F., Xie L., et al. (2012). "Prophylactic chemotherapy for hydatidiform mole to prevent gestational trophoblastic neoplasia". Cochrane Database Syst Rev, 10 (10), pp. Cd007289.

4. Giorgione $V_{.}$, Bergamini A., Cioffi $R_{.}$, et al. (2017). "Role of Surgery in the Management of Hydatidiform Mole in Elderly Patients: A SingleCenter Clinical Experience". Int J Gynecol Cancer, 27 (3), pp. 550-553.

5. Kaye D. K. (2002). "Gestational trophoblastic disease following complete hydatidiform mole in Mulago Hospital, Kampala, Uganda". Afr Health Sci, 2 (2), pp. 47-51.

6. Savage P. M., Sita-Lumsden A., Dickson S., et al. (2013). "The relationship of maternal age to molar pregnancy incidence, risks for chemotherapy and subsequent pregnancy outcome". J Obstet Gynaecol, 33 (4), pp. 406-11.

7. Wang Q., Fu J., Hu L., et al. (2017), "Prophylactic chemotherapy for hydatidiform mole to prevent gestational trophoblastic neoplasia". Cochrane Database Syst Rev, 9, pp. Cd007289.

8. Zhao P., Chen Q., Lu W. (2017). "Comparison of different therapeutic strategies for complete hydatidiform mole in women at least 40 years old: a retrospective cohort study". BMC Cancer, 17 (1), pp. 733.

\section{ĐẶC ĐIỂM PHÁT TRIỂN TÂM-VÂ̂N ĐộNG Ở TRẺ TỰ KỶ TỪ 24 ĐẾN 72 THÁNG TUỔI TẠI THÁI NGUYÊN}

\section{Lê Thị Kim Dung*, Nguyễn Thị Xuân Hương*, Hoàng Thị Huế*, Nguyễn Thị Phượng*, Bế Hà Thành*, Trần Tuấn Anh*}

\section{TÓM TẮT.}

Mục tiêu: Mô tả đặc điểm phát triển tâm-vận động ở trẻ từ 24 đến 72 tháng tuổi mắc rối loạn tự kỷ. Đối tượng và phương pháp: Nghiên cứu mô tả được thực hiện trên 161 trẻ từ 24 đên 72 tháng tuổi mắc rối loạn tự kỷ tại Thái Nguyên, thời gian từ năm 2014 đến 2017. Tự kỷ được chẩn đoán xác định theo tiêu chuẩn DSM-IV và phần loại mức độ theo thang điểm đánh giá tự kỷ (CARS), đặc điểm phát triển tâmvận động được đánh giá bằng test Denver II. Kết quả: Tuổi trung bình được chẩn đoán tự kỷ 29,87 \pm 4,2 tháng, tự kỷ gặp nhiều ở trẻ nam hơn trẻ nứ, tỉ lệ nam/nữ = 4,75/1; tự kỷ mức độ nặng chiếm tỉ lế khá cao $(70,2 \%)$. Trẻ tự kỷ chậm phát triển nhiều nhất ở

*Trường Đại học Y- Dược Thái Nguyên Chịu trách nhiệm chính: Lê Thị Kim Dung Email: lethikimdung@tnmc.edu.vn Ngày nhận bài: 19.3.2021

Ngày phản biện khoa học: 14.5.2021

Ngày duyệt bài: 25.5.2021 các lĩnh vực liên quan đến giao tiếp như: châm phát triển ngôn ngữ (95,03\%); chậm phát triển lĩnh vực cá nhân-xã hội $(95,65 \%)$. Khoảng 73,91\% trẻ tự kỷ chậm phát triển vận động tinh tế, thích ứng và $25,47 \%$ trẻ tự kỷ chậm phát triển vận động thô. Trẻ tự kỷ chậm phát triển ở mức vừa và nặng $(\mathrm{DQ}<50)$ chiếm tỉ lê $59,0 \%$. Kết luân: Trẻ tự kỷ chậm phát triển nhiêu nhất ở các lĩnh vực liên quan đến giao tiếp như: chậm phát triển ngôn ngữ, chậm phát triển lînh vực cá nhân-xã hội $(95,65 \%)$. Trè tự kỷ chậm phát triển ở mức vừa và năng $(\mathrm{DQ}<50)$ chiếm tỉ lệ $59,0 \%$

Tư khóa: Tự kỷ, trắc nghiệm Denver II, ngôn ngữ, cá nhân-xã hội, phát triển tâm-vận động

\section{SUMMARY \\ CHARACTERISTICS OF PSYCHIATRY AND \\ MOVEMENT DEVELOPMENT IN CHILDREN WITH AUTISM FROM 24-72 MONTHS IN THAI NGUYEN \\ Objectives: Describe the characteristics of} psychiatry and movement development in children from 24 to 72 months of age with an autism spectrum 